فاعلية توظيف الموديولات التعليمية في تدريس مادة النحو على زيادة التحصيل الدراسي واتجاه طلاب الصف الثاني

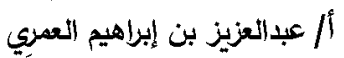

\title{
فاعلية توظيف الموديولات التعليمية في تدريس مادة النحو على زيـادة التحصيل الدراسي واتجاه طلاب الصف الثاني الثانوي نحوها
}

\author{
إعـلداد \\ عبدالعزيز بن إبراهيه العمَرِي \\ مشرف مصادر التعلم بالإدارة العامة للتعليم بالرياض
}


فاعلية توظيف الموديولات التعليمية في تدريس مادة النحو على زيادة التحصيل الدراسي واتجاه طلاب الصف الثاني أ/عبدالتعزيز بن إبراهيم العمبري

الثانوي نحوها

\section{المستخلص:}

هدفت الدراسة الحالية إلى الكثف عن فاعلية استخدام الموديولات التعليمية في تدريس مادة النحو على تنمية التحصيل الاراسي لاى طلاب الصف الثاني الثانوي. والتعرف على فاعلية استخدام الموديولات التعليمية في تدريس مادة النحو على تتمية الاتجاه نحو الماده لاى طلاب الصف الثاني الثانوية، وقد توصلت الدراسة إلى:وجود فرق ذي دلالة إحصائية عند مستوى (1+..) بين متوسطي درجات طلاب المجموعة

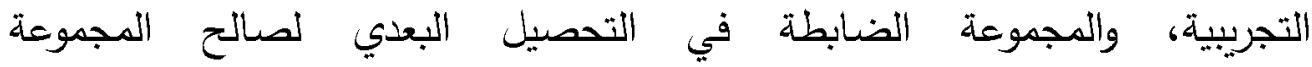
التجريبية.ووجود فرق ذي دلالة إحصائية عند مستوى (0. . .) بين متوسطي درجات طلاب المجموعة التجريبية في التطبيق القبلي والبعدي لمقياس الاتجاه نحو المادة لصالح التطبيق البعدي.

الكلمات المفتاحية : المديولات التعليمية ـ التحصيل ـ الاتجاه ـ النحو ـ طلاب الثانوي . 
فاعلية توظيف الموديولات التعليمية في تدريس مادة النحو على زيادة التحصيل اللراسي واتجاه طلاب الصف الثاني

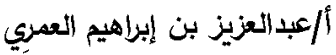
الثانوي نحوها

Effectiveness of the employment of educational modules in the teaching of grammar on the increase of academic achievement and the direction of secondary secondary students towards it.

\section{Abdulaziz bin Ibrahim Al-Omari}

\section{Abstract:}

Summary :The present study aimed at detecting the effectiveness of the use of educational modules in the teaching of grammar on the development of academic achievement among second grade secondary students. And to identify the effectiveness of the use of educational modules in the teaching of grammar on the development of the trend towards the material in the second grade secondary students. results, the most important of which are: the existence of a difference of statistical significance at the level of (0.01) between the average scores of the experimental group and the control group in the post-achievement in favor of the experimental group. Statistics at the level of (0.05) between the average scores of the experimental group students in the tribal and remote application of the measure of the trend towards the material in favor of the post application.

Keyword: Educational fees - Collection - Direction - GrammarSecondary students . 
فاعلية توظيف الموديولات التعليمية في تدريس مادة النحو على زيادة التحصيل الدراسي واتجاه طلاب الصف الثاني أ/عبدالتعزيز بن إبراهيم العمبري

الثانوي نحوها

\section{مقدمة}

تؤدي اللغة العربية دوراً أساسياً في حياء القرد عامة والمتعلم خاصة، فعن طريقها تنمو شخصيته ويتفاعل مع بيئته ومجتمعه، وهي وسيلة الاتصال وأداة لتحصيل

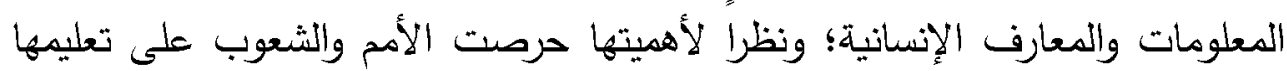

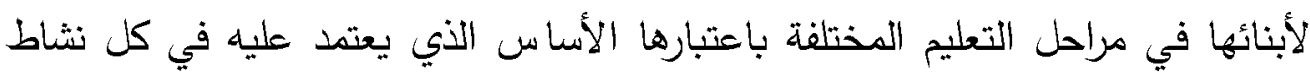

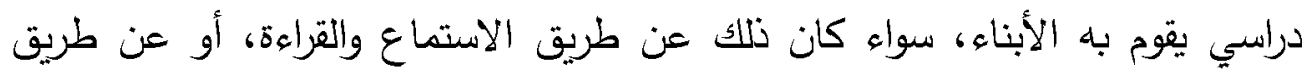
الحديث والكتابة ولهذا تظل قدرة المتعلم اللغوية خير معين له على التحصيل المعرفي فراهي والمهاري في جميع التخصصات. لذلك أولت سياسة التعليم في المملكة العربية السعودية تعليم اللغة العربية عناية فائقة في جميع المراحل التعليمية عامة وفي المرحلة الثانوية خاصة، كونها آخر مراحل التعليم العام.

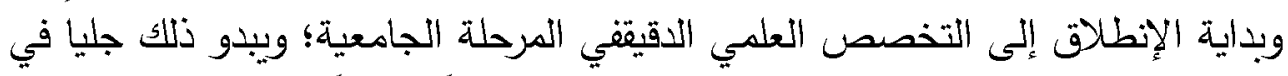
تطوير مناهجها، والسعي لإعداد المعلمين المؤهلين علميا وتربويا لتتريس موادها، وعقد الاورات التدربية لهم أثثاء الخدمة. ويعد النحو فرعاً من فروع اللغة العربية التي لها

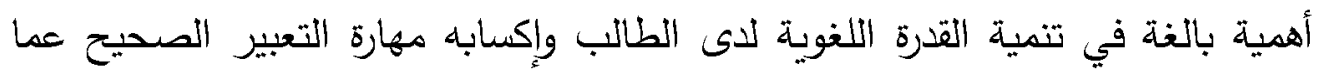
يجيش في صدره من أفكار وما يدور في ذهنه من معان؛ وهذا ما جعل المخططين للتعليم يفردون له ما نسبته (• ع\%) من مجموع الوقت المخصص لتعليم فروع اللغة

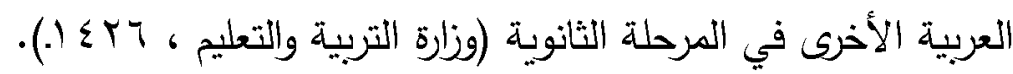
وبالرغم من هذا الاهتمام إلا أن الشكوى تتزايد من صعوبته وتدني مستوى المتعلمين فيه بصفة عامة؛ حيث تثير نتائج الاراسات والبحوث إلى إنخفاض مستوى تحصيل الطلاب فيه مؤكدة على ضرورة معرفة أسباب الضعف، ووضع البرامج لعلاجها

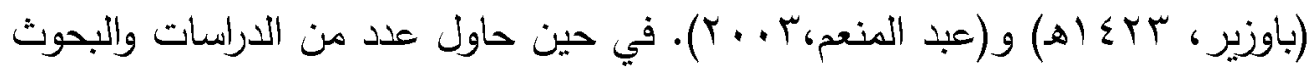
الكثف عن أسباب ضعف الطلاب في مادة النحو بهاف تشخيصها وإيجاد الحلول

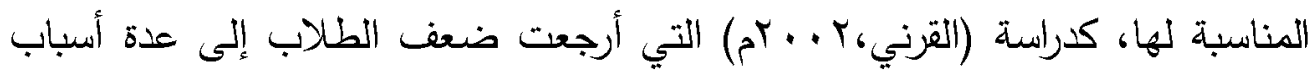
منها: صعوبة المادة ذاتها، وضعف مستوى معلمي اللغة،وانتشار اللهجة العامية. أما 
فاعلية توظيف الموديولات التعليمية في تدريس مادة النحو على زيادة التحصيل الدراسي واتجاه طلاب الصف الثاني أ/عبدالتعزيز بن إبراهيم العمبري

الثانوي نحوها

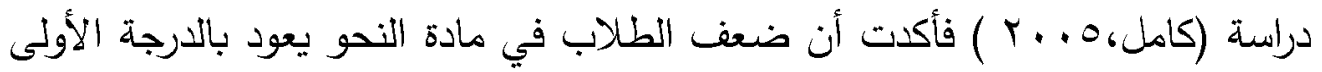

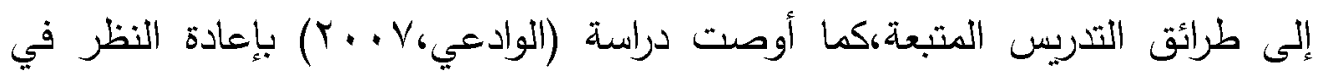
طرائق تدريس مادة النحو في المراحل التعليمية المختلفة، في حين أدرك المسؤولون في وزارة التزبية والتعليم وفي الجامعات السعودية ما يعانيه الطلاب من ضعف لنف لغوي فعقدت بعض الندوات لمناقثة أبعاد هذه الظاهرة كان من أهمها ندوة كلية المعلمين بحائل (عاع اهـ)، والتي تناولت تحديد الأخطاء اللغوية ومظاهرها، واقترحت بعض الحلول لمعالجتها، ثم تبعتها ندوة جامعة الإمام محمد بن سعود (T أع اهـ)، والتي كان من توصياتها إصلاح مناهج تعليم اللغة العربية في جميع مراحل التعليم،وطرائق

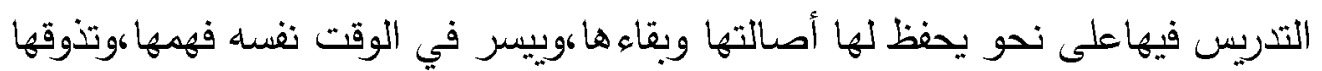
واستعمالها. وفي ميدان البحث التربوي حاولت العديد من البحوث والدراسات التجريبية التغلب على هذه الظاهرة من خلا تدريس النحو بطرائق واستراتيجيات حديثة، كدراسة البكر (Tr \& أه) التي استخدمت التعلم التعاوني في تدريس النحو لطلاب المرحلة المتوسطة كما استخدمت دراسة الفيفي (آسع اهـ ) خرائط المفاهيم في تدريس قواعد اللغة لتلاميذ

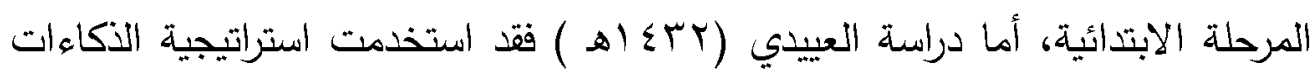

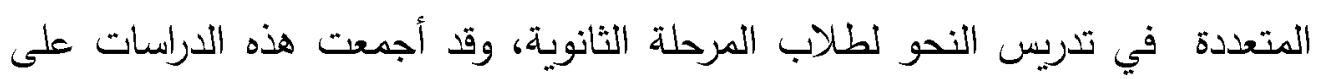
أن السبب الرئيس لتدني مستوى التحصيل الدراسي عند المتعمين يعود إلى جمود طرائق التدريس المستخدة في تدريس مادة النحو، والالتزام بها في المدارس، ويؤكد ذلك ارتفاع تحصيل الطلاب عقب تدريهم بهذه الاستراتيجيات ، ومن هنا فقد بات التعلم الذاتي من أهم الاتجاهات الحديثة التي تدعو لهم تطلبات هذا العصر لأنه يقوم

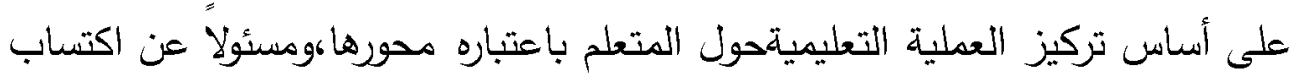
المعلومات والحقائق بما يؤدي في النهاية إلى تعليمه كيف يتعلم (جامل، بـ . r). 
فاعلية توظيف الموديولات التعليمية في تدريس مادة النحو على زيادة التحصيل الدراسي واتجاه طلاب الصف الثاني أ أعبدالعزيز بن إبراهيم العمبري

الثانوي نحوها

\section{مثكلة الدراسة:}

لقد أشارت العديد من الدراسات إلى أن التعليم يكون أكثر فاعلية عندما يكون للمتعلمين دور إيجابي وذلك من خلال الاستراتيجيات التي تؤدي إلى تحصيلهم للمعارف والمهارات والاتجاهات المطلوبة بأنفسه من خلال مرورهم بمواقف تعليمية متنوعة تستثير دوافعهم للتعلم وتزيد من قدرتهم على الاعتماد على أنفسهم ومنها التعلم باستخدام الوحدات التعليمية المصغرة (الموديولات Modules). السعيد

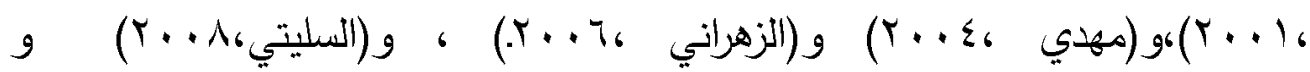
- (Corn,2001 ) و (Hernandez,2008) وتعد ( الموديولات التعليمية ) من أهم استراتيجيات التعلم الذاتي التي شاع استخدامها في كثير من دول العالم لفاعليتها وتركيزها على نشاط المتعلمكما أنها تمثل اتجاها

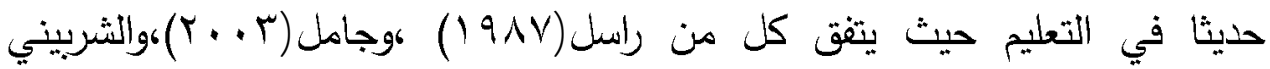

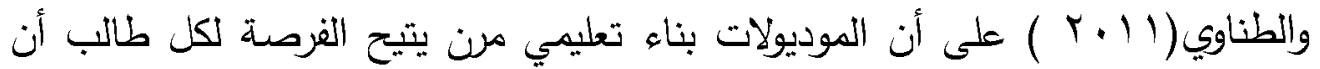

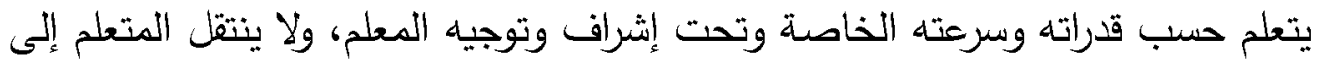
دراسة جزه تال من المادة الدراسية إلا بعد أن يتقن تعلم الجزء السابق عن طريق تراكم

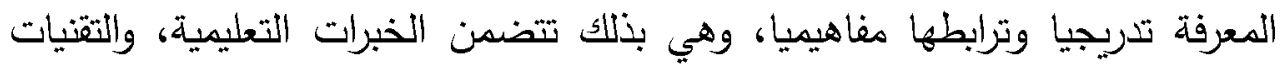
والأنشطة المتنوعة، والبدائل التي يختار منها الطالب ما يتلاءم مع ظروفه وقدراته وبما يحقق أهداف الموديول التعليمي. انطلاقاً من مناداة الكثير من الدراسات بضرورة تطبيق استراتيجيات حديثة في تدريس مواد اللغة العربية، وذلك لمعرفة مدى فاعليتها في إثراء العملية التعليمية، ورفع مستوى التحصيل الا راسي، ونظرا لما لاحظه الباحث من تدني مستوى الطلاب في مادة النحو من خلال خبرته العملية في تدريس مواد اللغة العربية واطلاعه على أوراق إجابات الطلاب ونتائج امتحاناتهم، واستنادا على نتائج الدراسة الاستطلاعية، ولعدم وجود دراسات- في حدود علم الباحث- تناولت استخدام الموديولات التعليمية كاستراتيجية تدريس لمادة النحو والصرف للصف الثاني الثانوي. بناء على ما سبق يمكن تحديد 
فاعلية توظيف الموديولات التعليمية في تدريس مادة النحو على زيادة التحصيل الدراسي واتجاه طلاب الصف الثاني أ أعبدالعزيز بن إبراهيم العمبري

الثانوي نحوها

مشكلة الدراسة في السؤال الرئيس التالي: ما فاعلية استخدام الموديولات التعليمية في تدريس مادة النحو على تنمية التحصيل الدراسي والاتجاه نحوا لمادة للى طلاب الصف الثاني الثانوي؟

ويتفرع من التساؤل الرئيس السابق التساؤلان الفرعيان التاليان: ا ـ ما فاعلية استخدام الموديولات التعليمية في تدريس مادة النحو على تنمية التحصيل الدراسي لاى طلاب الصف الثاني الثانوي؟ Y. ما فاعلية استخدام الموديولات التعليمية في تدريس مادة النحو على الاتجاه نحو المادة لدى طلاب الصف الثاني الثانوي؟

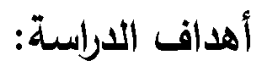

r. الكثف عن فاعلية استخدام الموديولات التعليمية في تدريس مادة النحو على تنمية التحصيل الدراسي لاى طلاب الصف الثاني الثانوي. ع. التعرف على فاعلية استخدام الموديولات التعليمية في تدريس مادة النحو على الاتجاه نحو المادة لدى طلاب الصف الثاني الثانوي.

أهمية الاراسة: - n

ا. أتثقر ميدان البحث العمي التربوي في المملكة العربية السعودية لمثل هذا النوع من الاراسات فالباحث لم يجد - على حد علمه - دراسة تناولت استخدام استراتيجية الموديولات التعليمية في تدريس مادة النحو والصرف للصف الثاني الثانوي. r. قد تساعد نتائج هذه الدراسة واضعي مناهج اللغة العربية في تخطيط وبناء مناهج قائمة على استراتيجية الموديولات التعليمية، لمواكبة تغيرات هذا العصر

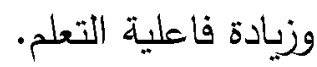


فاعلية توظيف الموديولات التعليمية في تدريس مادة النحو على زيادة التحصيل الدراسي واتجاه طلاب الصف الثاني أ/عبدالتعزيز بن إبراهيم العمبري

الثانوي نحوها

\section{حدود الادراسةة:}

اقتصرت حدود الاراسة على ما يلي:

الحدود الموضوعية: مقرر النحو والصرف للصف الثاني الثانوي الثرعي، وحدة بناء

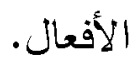

الحدود الزمانية:طُقتت هذه الدراسة في الفصل الدراسي الأول للعام الدراسي بrإ اهـ-

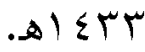

الحدود المكانية:تم تطبيق هذه الدراسة على عينة من طلاب الصف الثاني الثانوي

الثرعي (حكومي، نهاري، بنين) بمدينة الرياض.

مصطلحات الاراسة:

1. فاعلية (Effectiveness) :يعرفها الباحث إجرائيًا بأنها: الأثر الإيجابي الأي يمكن

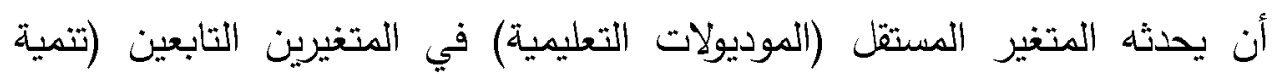

التحصيل الدراسي،والاتجاه نحو المادة) لدى طلاب الصف الثاني الثانوي بمدينة

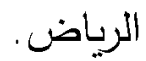

r. الموديولات التعليمية (Educational modules) :يعرفها الباحث إجرائياً بأنها:وحدة

تعليمية صغيرة تقوم على مبدأ التعلم الذاتي، وتحوي مجموعة محددة من الأهداف

السلوكية يسعى المتعلم إلى تحقيقها عن طريق سلسة من التوجيهات والخبرات

والنشاطات والتتريبات إضافة إلى أساليب التقويم الذاتية التي توضح للمتعلم مقدار

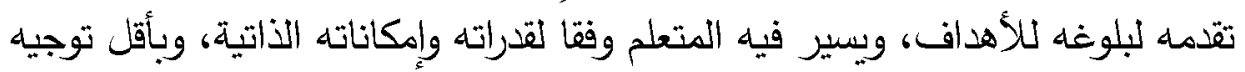

من المعلم.

r. الاتجاه نحو المادة:يعرفها الباحث إجرائياً بأنها: المحصلة الايجابية أو السلبية

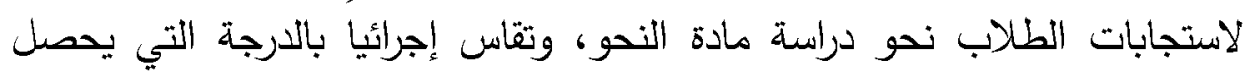

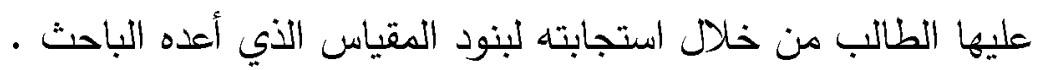
• الإطار النظري 
فاعلية توظيف الموديولات التعليمية في تدريس مادة النحو على زيادة التحصيل الدراسي واتجاه طلاب الصف الثاني أ أعبدالعزيز بن إبراهيم العمبري

الثانوي نحوها

أولا: التعلم الذاتي : يستند التعلم الذاتي إلى عدد من الأسس الفسيولوجية، والنفسية، والتربوية، والفلسفية،ولقد اشار (جامل، + . rمصع ()) وهي:اعتبار كل طالب حالة خاصة في تعلمه، ومراعاة مبدأ الفروق الثردية في التعليم،والتحديد الاقيق للسلوك المبئي للتعلم الهادف،ومراعاء السرعة الذاتية لكل طالب أثناء التعلمهوتقسيم المادة التعليمية إلى خطوات صغيرة هادفة،والإيجابية والمشاركة في التعلم،والتسلسل المنطقي لخطوات التعلموالتعزيز الفوري، والتغذية الراجعة بعد كل خطوة،وحرية الحركة أثناء التعلم، وحرية اختيار المواد التعليمية. وفي ضوه ذلك يتضح أن التعلم الذاتي ينطلق من حاجات الطلاب،ورغباتهم وقدراتهم إذ في ضوئها تقرر طبيعة المنهج الدراسي،والمناشط التي ينبني للطلاب ممارستها وهذه الأسس تنطبق على جميع أساليب التعلم الذاتي.( 50 (Soeharto,2009)

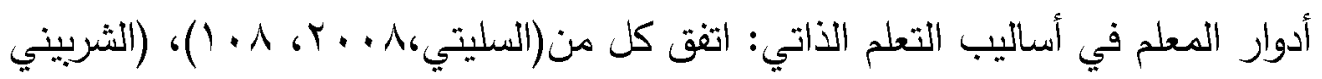

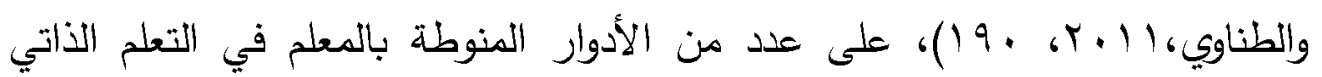
يلخصها الباحث في التعرف على خبرات الطلاب السابقة وقدراتهم وميولهم واهتماماتهخ واتجاهاتهم، ومنها تخطيط المواقف التعليمية بما يتناسب مع قدرات الطلاب، وخبراتهم وكذلك التعرف إلى حاجات الطلاب ورغباتهم ووضع خطة دراسية لكل طالب، ومتابعة تقدمه فيها، وتزويد الطالب بالمعلومات، والوسائل اللازمة لمساعدته على تقويم تقدمه ذاتيا، وإعداد البيئة التعليمية المناسبة للتعلم الذاتي، عن طريق تنظيم الصف الدراسي لهي وتشخيص الصعوبات التي تواجه الطلاب، ووضع الحلول لهاهوتقديم التوجيه والإششاد للطلاب أثناء تعلمه،وتعزيز ذاتية الطالب، وذلك بمساعدته لاستعادة ثقته بنفسه وتعلم خبرات جديدة بإقامة النشاطات التعليمية المتنوعة، ليختار منها ما يتناسب مع قدراته، وإمكاناته، وحاجاته.

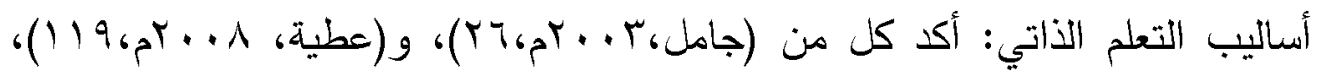

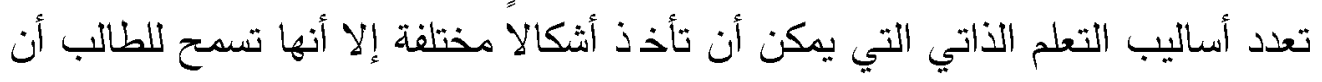
يسير وفق سرعته الخاصة، وتوفر له أساليب التغذية الراجعة؛ لمعرفة صحة استجاباته 
فاعلية توظيف الموديولات التعليمية في تدريس مادة النحو على زيادة التحصيل الدراسي واتجاه طلاب الصف الثاني أ أعبدالعزيز بن إبراهيم العمبري

الثانوي نحوها

بعد أن تقدم له أنواعاً متعددة من التعزيز تكفل زيادة دافعيته للتعلم ومنها: التعليم المبرمج،التعليم عن بعد،الرزم التعليمية التعلم باستخدام الوحدات التعليمية الصغيرة(الموديولات).

الموديولات التعليمية Educational modules مجالات استخدام الموديولات التعليمية:الموديولات التعليمية بناء مرن يمكن استخدامها في مجالات تعليمية متعددة، وقد اتفقت العديد من الأدبيات التربوية على عدد من تلك المجالات، يلخصها الباحث فيما يلي: التعليم بمراحله المختلفة: أكدت العديد من الاراسات والبحوث فاعلية استخدام

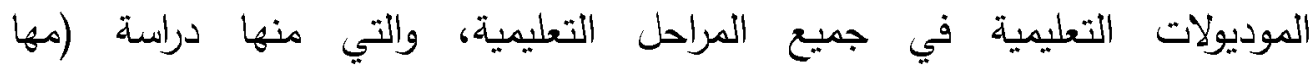
الصبحي، + . r) التي أثتبت فعالية المديولات التعليمية في تنمية بعض مهارات قواعد النحو لاى تلميذات الصف الأول من المرحلة المتوسطة، وعلى مستوى المرحلة الثانوية توصلت دراسة (التركي، 9 ج.ب) إلى فاعلية التدريس بالموديولات التعليمية في تنمية التحصيل الدراسي في مقرر الحاسب الآلي لطلاب الصف الأول الثانوي بالمعاهد العلمية، وتتميز دراسة (بهلول،r +.r) بمجتمع الدراسة المكون من طلاب الاراسات العليا -ماجستير - والتي توصلت إلى فعالية استخدام الموديولات التعليمية في تدريس مادة المناهج في كل من التحصيل الدراسي والاتجاه نحو التعلم الذاتي وتحقيق الذات للى طلاب الدراسات العليا تخصص لغة هربية. إثراء التعليم والتعلم: تسهم الموديولات التعليمية في إثراء التعلم والتعليم لدى الطلاب، حيث يوجد في كل مجال من مجالات المواد الدراسية عدد كبير من الموضوعات التي يرغب الطلاب ذوي القدرات والافعية العالية للتعلم في متابعة دراستها لتحقيق مزيد من المعرفة، وربما يسهم استخدام الموديولات التعليمية في مناهج التعليم العام في توسيع مدارك الطلاب وتنمية مهاراتهم العلمية والبحثية، كما يمكن أن تساعد في توضيح عناصر المقرر المختزلة، أو كحل لاستكمال المقررات الطويلة التي قد لا يسمح ضيق الوقت باستكمالها. ( Bolka,2003,78) 
فاعلية توظيف الموديولات التعليمية في تدريس مادة النحو على زيادة التحصيل الدراسي واتجاه طلاب الصف الثاني أ أعبدالعزيز بن إبراهيم العمبري

الثانوي نحوها

التعليم العلاجي: هناك طلاب تو اجههم صعوبات في التعلم نظراً لزيادة عددهم في الفصل الدراسي التي قد لا تمكن المعلم من إعطاء اهتمامه لكل الطلاب، وبالتالي لا يتمكن مثل هؤلاء من الحصول على القدر الكافي من المساعدة التي يحتاجونها من المعلم وهنا يمكن للموديول التعليمي أن يتغلب على الضعف الموجود عند هؤلاء الطلاب وقد أثتتت بعض الدراسات التي أجريت فاعلية الموديولات التعليمية وقدرتها على التغلب على بعض نقاط الضعف عند الطلاب كدراسة (جواهر مهاي،بr 1 (ه) التي أثبتت فعَّالية المجمعات التعليمية في علاج الأخطاء الإملائية الأكثر شيوعاً لاى لئ طالبات الفرقة الرابعة بقسم اللغة العربية بجامعة الملك عبدالعزيز ،وكدراسة (السيد 1900، ام) التي قدمت برنامجا علاجيا باستخدام الموديولات التعليمية للطلاب منخفضي التحصيل في الهندسة بالمرحلة الإعدادية. التعليم عن بعد: أشار (منصور ،r+..rم) إلى أن الجامعات الأمريكية المفتوحة قد اعتمدت في تصميم مقرراتها على نظام الموديولات التعليمية ، إذ تتيح لكل طالب الدراسة وفقا لظروفه الخاصة.

\section{خصائص ومميزات الموديولات التعليمية:}

يتفرد الموديول التعليمي بخصائص تميزه عن غيره من أساليب التعلم الذاتي الأخرى، منها

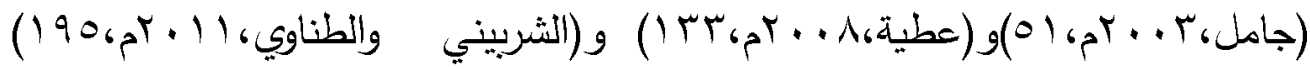
مايلي:الحرية : حيث يسمح الموديول التعليمي للطلاب أن يتعموا بأنفهه، ويوفر لهم الوقت الكافي، بالإضافة إلى أنه يوفر الظروف التي تجعل الطالب إيجابياً في الموقف لئف التعليمي. 
فاعلية توظيف الموديولات التعليمية في تدريس مادة النحو على زيادة التحصيل الدراسي واتجاه طلاب الصف الثاني أ/عبدالعزيز بن إبراهيم العمبري

الثانوي نحوها

المرونة: وذلك في اختيار المواد والتقنيات التعليمية، وزمان الدراسة ومكانها من جانب الطالب، أما من جانب المعلم فيتحرر من كثير من أعمال التدريس الروتينية. إيجابية الطلاب: من خلال مشاركتهم النشطة في مواقف التعلم والتعليم؛ والتقويم الذاتي لأنفسهم، وإتاحة الفرصة لإعادة الدراسة مرة أخرى في حال عدم الوصول إلى المستوى المطلوب. الوحدة الموضوعية: فالموديول التعليمي يعالج موضوعا محدا، ويتوقف مستوى وحجم الموضوع على طبيعة المرحلة التعليمية، وطبيعة الموضوع الدراسي. التعلم من أجل الإتقان: حيث يشترط إتقان الوحدة الدراسية بمستوى لا يقل عن (. (ه) \% قبل الانتقال إلى الوحدة التالية، ويختلف مستوى الإتقان باختلاف كل من المهمة التعليمية المطلوبة، وطبيعة المادة الدراسية، والطالب، والمواقف التعليمية والإمكانات المتاحة. استخد ام المدخل المنظومي: حيث يتكون نظام التعليم- على اختلاف أشكاله - من أربعة مكونات، هي : المدخلات، والعمليات، والمخرجات، والتغذية الراجعة واستخدم المذخل المنظومي في تصميم الموديول التعليمي يعني أن كل خطوة في عملية تصميم الموديول ترتبط بالخطوات التي قبلها وبعدها تأثرا وتأثيرا. سهولة الاستخدام والتداول: إذ يمكن استخدام الموديول التعليمي في المدرسة أو المنزل، فهناك حرية في مكان وزمان استخدامه، إضافة إلى إمكانية تخزينها والوصول إليها عند الحاجة.

استمرارية وفورية التقويم: من خلا توفير أساليب عديدة للتقويمتكون في شكل اختبارات ذاتية، قبلية، أو بعدية، هذا بالإضافة إلى التقويم التكويني أثناء دراسة محتوى الموديول.

منهج الاراسة:اختار الباحث المنهج شبه التجريبي، الذي عرفه العساف (ابـأهـ ص (YVV) بأنه "المنهج الذي يستطيع الباحث بواسطته أن يعرف أثر السبب( المتغير المستقل) في النتيجة (المتغير التابع)" وذلك لمناسبته لطبيعة الدراسة وقد قام الباحث 
فاعلية توظيف الموديولات التعليمية في تدريس مادة النحو على زيادة التحصيل الدراسي واتجاه طلاب الصف الثاني أ أعبدالعزيز بن إبراهيم العمبري

الثانوي نحوها

بإجراء التجربة على مجموعتين إحداهما تجرببية،والأخرى ضابطة ولمعرفة الفرق بينهماقام الباحث بدراسة فاعلية العامل المستقل (الموديولات التعليمية) على المتغيرين التابعين ( التحصيل الدراسي) و(الاتجاه نحو المادة).

مجتمع الدراسة:تكوَّن مجتمع لدراسة من جميع طلاب الصف الثاني الثانوي الشرعي بالمدارس الثانوية الحكومية النهارية بمدينة الرياض في الفصل الدراسي الأول من العام

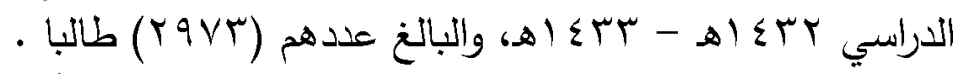

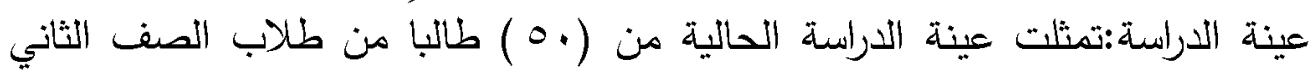
الثانوي الشرعي مقسمين إلى مجموعتين متكافتتين تجريبية وضابطة تم اختيارهما بالطريقة العشوائية العنقودية متعددة المراحل.

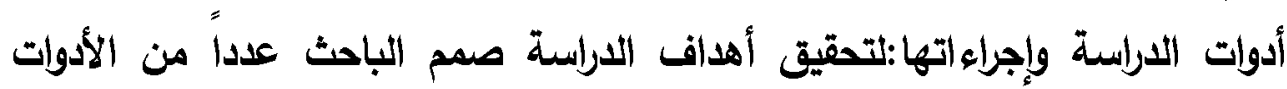
تمثلت فيما يلي: الموديولات التعليمية: قام الباحث بإعداد ثُلاث موديولات تعليمية وذلك باتباع

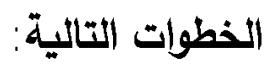
تحديد الموضوعات التي سيتم تدريها باستخدام الموديولات التعليمية،والتي تتوافق مع الخطةالدراسية للمادة، والمتزامنة مع فترة تطبيق الدراسة، فوقع الاختيار على وحدة بناء الأفعال ثم وزعت الموديولات على النحو التالي: الموديول الأول: الفعل الماضي، الموديول الثاني: فعل الأمر، الموديول الثالث: الفعل المضارع.

\section{وقد تكونت الموديولات التعليمية مما يلي:}

المقدمة: وتتضمن نظرة شاملة تبين موضوع الموديول وأهميته، وطريقة السير فيه. الأهداف السلوكية للموديول: وقد روعي فيها شروط صياغة الأهداف السلوكية. لمحتوى التحليمي للموديول وقد روعي فيه ثراء المعلومات وحداثتها، ودقتها،اشتقاقها من المقرر - كتاب النحو - بما يضمن سيرها في إطار محدد، حتى لا تكون أقل أو أعلى 
فاعلية توظيف الموديولات التعليمية في تدريس مادة النحو على زيادة التحصيل الدراسي واتجاه طلاب الصف الثاني أ/عبدالتعزيز بن إبراهيم العمبري

الثانوي نحوها

من مستوى الطالب، وعرضها بأسلوب سهل ممتع يعزز من إمكانية تعلمها،الاستفادة من الاستراتيجيات الحديثة في عرض المحتوى.

النشاطات التعليمية: وقد تكون كل موديول من ثلاثثة نشاطات تعليمية.

الاختبار التحصيلي :للإجابة على أسئلة الاراسة استخدم الباحث الاختبار التحصيلي القبلي والبعدي كأداة تناسب طبيعة الاراسة وتحقق أهدافها ،واشتمل الاختبار على(·)سؤالا من نوع الاختيار من متعدد، وقد سار الباحث في إعداد الاختبار وفق الخطوات التالية:

تحديد الهدف العام من الاختبار:كان الهدف العام من الاختبار هو قياس مستوى تحصيل طلاب الصف الثاني الثانوي الثرعي - عينة الاراسة - للمعلومات المتضمنة في مقرر مادة التحو - وحدة بناء الأفعال-، وذلك قبل وبعد تذريسهم باستخدام الموديولات التعليمية والتعرف على مستوى تحصيلهم عند المستوبات المعرفية الستة لبلوم. تحليل المحتوى الاراسي:قام الباحث باختيار الفصل الاراسي الأول من مقرر النحو

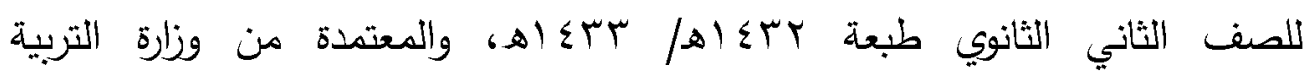
والتعليم،واختار الباحث وحدة بناء الأفعال. تحديد الأهداف التعليمية للمحتوى :قام الباحث بصياغة الأهداف التعليمية للموضوعات

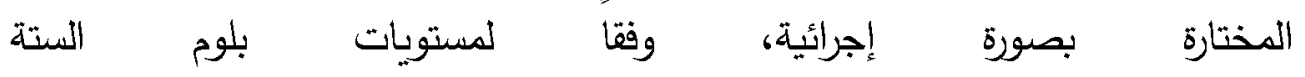
وهي:(التتكر ،الفهم،التطبيق،التحليل،التركيب،التقوب) ثخ عرضت على مجموعة من المحكمين لإبداء ملحوظاتهم حولها.

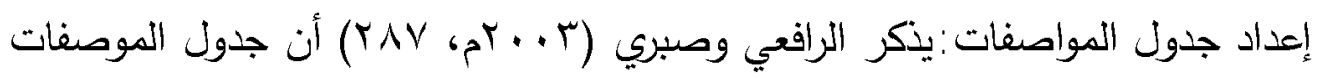
عبارة عن "جدول له بعدان يمثل أحدهما محتوى الوحدة (الموضوعات)، ويمثل الآخر مخرجات التعلم (الأهداف) المرتبطة بهذا المحتوى" وقد قام الباحث بإعداد جدول الموصفات التالي: 
فاعلية توظيف الموديولات التعليمية في تدريس مادة النحو على زيادة التحصيل الدراسي واتجاه طلاب الصف الثاني أ أعبدالعزيز بن إبراهيم العمنري

الثانوي نحوها

الجدول ا يوضح مواصفات الاختبار

\begin{tabular}{|c|c|c|c|c|c|c|c|}
\hline \multirow{2}{*}{ الأسئلة } & \multicolumn{6}{|c|}{ مستوى الأهداف } & \multirow{2}{*}{ الموضو عات } \\
\hline & التقويم & التركيب & التحليل & التطبيق & الفهم & التذكر التر & \\
\hline 1 & 1 & 1 & 1 & $r$ & $r$ & $r$ & الفعل الماضي \\
\hline IT & r & 1 & r & r & r & $r$ & فعل الأمر \\
\hline$\Lambda$ & 1 & r & 1 & 1 & 1 & r & الفعل المضار ع \\
\hline$r$. & $\varepsilon$ & $\varepsilon$ & $\varepsilon$ & 7 & 7 & 7 & مجموع الأسئلة \\
\hline$\% 1 \ldots$ & $1 \pi .4$ & $1 \pi .4$ & T.T & r. & $r$. & $r$. & النسبة المئوية \\
\hline$r$ & $\varepsilon$ & $\varepsilon$ & $\varepsilon$ & 7 & 7 & 7 & مجموع الدرجات \\
\hline$\% 1 \ldots$ & IT. & $1 \pi .4$ & T.r & $r$. & $r$. & $r$. & الأهمية النسبية \\
\hline
\end{tabular}

صياغة أسئلة الاختبار :قام الباحث بصياغة الأسئلة على نمط الاختبارات الموضوعية، الماته والتي يقصد بها عند فتح الله (9rع (هـ، صهrr)"تلك الاختبارات التي تتكون من أسئلة مغلقة، إجابتها الصحيحة محددة لا خلاف حولها ،ويقصد بالموضوعية ألا تتأثر

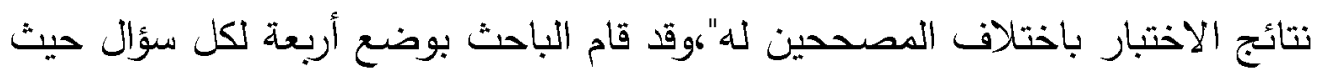
إن زيادةعدد البدائل يقلل من التخمين الأي يعد عيبا في الاختبارات الموضوعية.

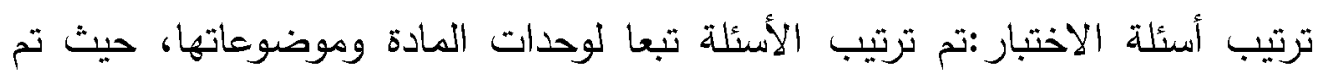
جمعا لأسئلة التي تدور حول موضوع واحد مع بعضها في الاختبار ،وتم ترتيبها فيما بينها تبعا للصعوبة.

صياغة تعليمات الاختبار:وقد راعى الباحث وضوح التعليمات ومناسبتها لمستوى الطلاب،واشتملها على توضيح الغرض من الاختبار ، وطريقة تسجيل الإجابة مع وضع مثال لذلك، وتوزيع الدرجات،بالإضافة إلى تخصيص مكان يسجل الطالب فيه بياناته . تجريب الاختبار على عينة استطلاعية:قام الباحث بتطبيق الاختبار على عينة تجريبية

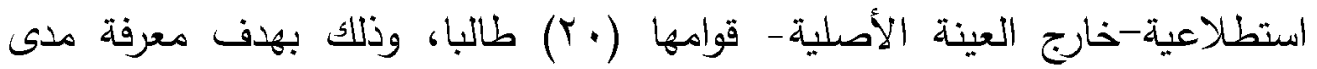
وضوح تعليمات ومفردات الاختبار،وتحديد زمن الاختبار، ومعاملات السهولة والصعوبة والثبات والتمييز للاختبار .

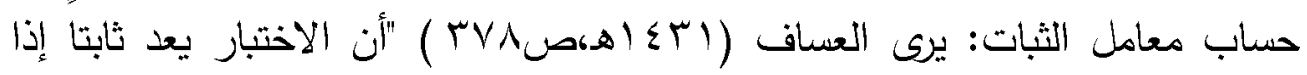
كان يؤدي نفس النتائج في حالة تكراره ، خاصة إذا كانت الظروف المحيطة بالاختبار 
فاعلية توظيف الموديولات التعليمية في تدريس مادة النحو على زيادة التحصيل الدراسي واتجاه طلاب الصف الثثاني

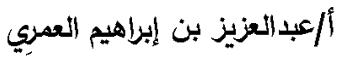

الثانوي نحوها

والمختبر متماثلة في الاختبارين"، ولقياس ثبات الاختبار استخدم الباحث (معادلة ألفا كرونباخ) (a) Cronbach's Alpha وجاءت نتائجها كالتالي: الجدول رقم ب يوضح معامل ألفا كرونباخ لقياس ثبات الاختبار

\begin{tabular}{|c|c|c|}
\hline ثبات المحور & عدد العبار ات & المحاور \\
\hline.$\wedge 1$ & r. & الثبات الكلى للاختبار \\
\hline
\end{tabular}

يتضح من النتائج أعلاه أن معامل الثبات للاختبار بلغ (Al. .) وهذا يدل على أن الاختبار يتمتع بدرجة مرتفعة من الثبات.

- وللتأكد من ثبات الاختبار ، استخدم الباحث (معادلة التجزئة النصفية)(Split- half) وجاءت نتائجها كالتالي:

الجدول رقم ايوضتح معامل التجزئة النصفية لقياس ثبات الاختبار

\begin{tabular}{|c|c|c|}
\hline الثبات & عدد العبار ات & \\
\hline.$\lambda r$ & 10 & معامل ثبات الجزء الأول \\
\hline.$\wedge \varepsilon$ & 10 & معامل ثبات الجزء الثاني \\
\hline
\end{tabular}

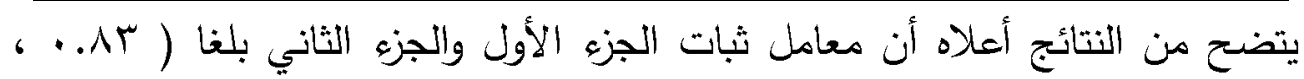
ع. . • على التوالي وهذا يدل على أن الاختبار يتمتع بدرجة مرتفعة من الثبات. حساب دعامل السهولة والصعوبة لمفردات الاختبار :هي إحدى مؤشرات الصلاحية للاختبارات وقا استخدم الباحث المعادلة التالية:

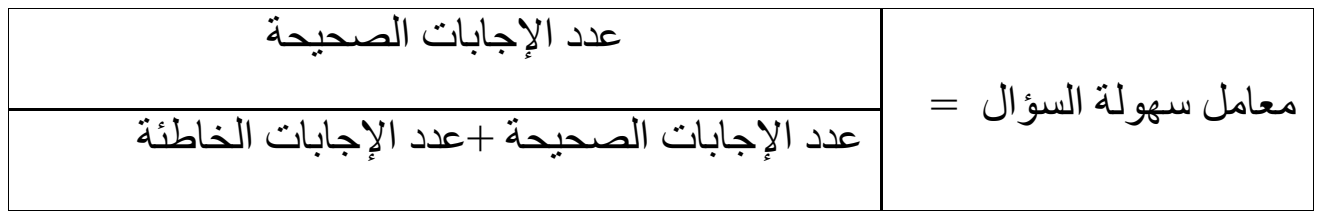

الجدول رقم ع يوضح معاملات السهوبة والصعوبة لناختبار ككل المائل

\begin{tabular}{|c|c|c|c|c|}
\hline الصعوبة معاملة & السهولة لة & الإجابات الخاطئة & الإجابات الصحيحة & عدد الأسئلة \\
\hline . & .71 & 19. & \&). & r. \\
\hline
\end{tabular}


فاعلية توظيف الموديولات التعليمية في تدريس مادة النحو على زيادة التحصيل الدراسي واتجاه طلاب الصف الثاني أ أعبدالعزيز بن إبراهيم العمبري

الثانوي نحوها

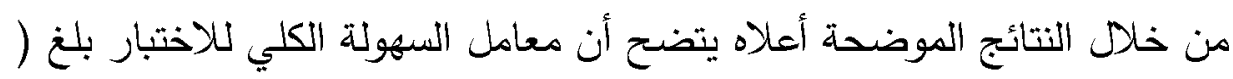

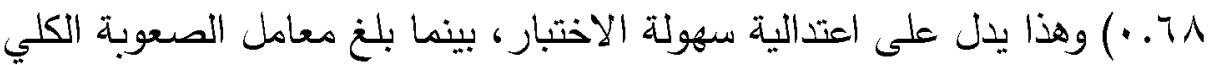
للاختبار (rr. · ) مما يدل على انخفاض صعوبة الاختبار وصلاحيته للتطبيق • الجدول رقم ه يوضح معامل التمييز للاختبار ككل

\begin{tabular}{|c|c|c|c|c|}
\hline معامل & حاصل طرح المجمو عة & الإجابات الصحيحة & الإجابات الصحيحة & عدد \\
\hline التمبيز & العليا من الدنيا & للمجمو عة الدنيا & للمجمو عة العليا & الأسئلة \\
\hline $.6 V \varepsilon$ & 111 & $\varepsilon$. & 101 & r. \\
\hline
\end{tabular}

من خلال النتائج الموضحة أعلاه يتضح أن معامل التمييز الكلي للاختبار بلغ (ع V.)، وهذا يدل على أن الاختبار يتمتع بدرجة متوسطة من التمييز يمكن الاعتماد عليها في التطبيق الميداني للدراسة. r r- r-r مقياس الاتجاهات:

اطلع الباحث على عدد من الدراسات التي استخدمت مقاييس الاتجاهات في تخصصات مختلفة وراجع بعض الأدبيات المتعلقة بالمقاييس، ليقف على خصائصها

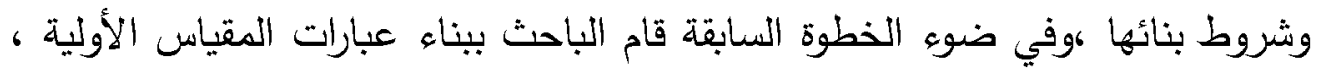
وقد بلغ عددها (Y) ) عبارة صيغت بأسلوب خبري سهل، نصفها عبارات موجبة، والنصف الآخر عبارات سالبة، ذات تدرج خماسي - حسب مقياس ليكرت- لقياس الاتجاهات.

صدق المقياس : للتأكد من صدق المقياس قام الباحث بعرض المقياس على عدد من ذوي الخبرة والاختصاص في مجال علم النفس والقياس والتقويم، بالإضافة إلى عدد من

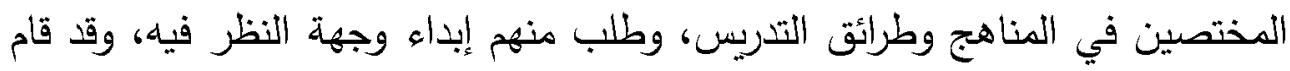
الباحث بإجراء التعديلات اللازمة في ضوه آراء المحكمين وملحوظاتهم بعدها قام الباحث بتطبيق المقياس على عينة تجربية استطلاعية-خارج العينة الأصلية - قوامها وماه ( ) ( ) طالبا، وذلك بهذف التحققمنصلاحية المقياس وقابليته للتطبيق بالإضافة إلى التحقق من صدق وثبات المقياس. 
فاعلية توظيف الموديولات التعليمية في تدريس مادة النحو على زيادة التحصيل الدراسي واتجاه طلاب الصف الثاني أ/عبدالعزيز بن إبراهيم العمبري

الثانوي نحوها

صدق الاتساق الاخلي للمقياس:استخدم الباحث معاهل الارتباط (بيرسون) لمعرفة الصدق الذاخلي للمقياس حيث تم حساب معامل الارتباط بين درجة كل عبارة من عبارات المقياس بالدرجة الكلية لعبارات المقياس ولقد أثارت النتائج أن قيم معامل ارتباط العبارات مع الدرجة الكلية للمقياس كانت دالة إحصائيا عند مستوى الدلالة

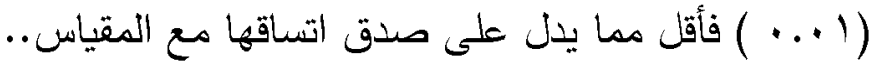
ثبات مقياس الاتجاهات: لقياس مدى ثبات مقياس الاتجاهات استخدم الباحث (معادلة

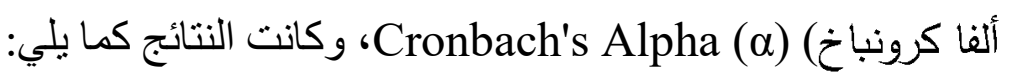
الجدول 7 يوضح معامل ألفا كرونباخ لقياس الثبات

\begin{tabular}{|c|c|c|}
\hline 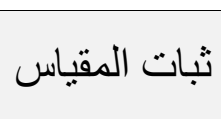 & 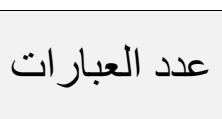 & مقياس اتجاه طلاب الثاني ثانوي شر عي نحو مادة \\
\hline$\because \wedge V$ & TE & معامل الثبات العام \\
\hline
\end{tabular}

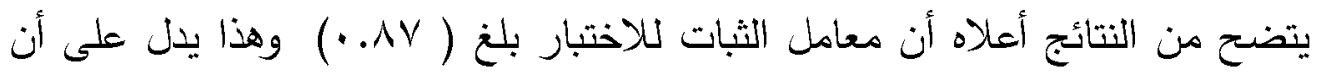
المقياس يتمتع بدرجة عالية من الثبات يمكن الاعتماد عليها في التطبيق الميداني للاراستة.

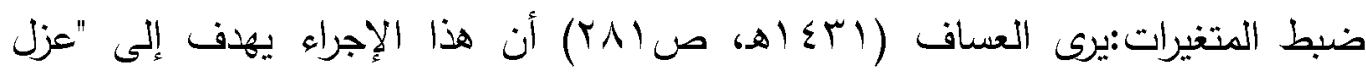
المتغيرات حتى يمنع أثرها على النتيجة،أوتثبيتها للتأكد من توافرها لدى المجموعتين "،لذا هاهي

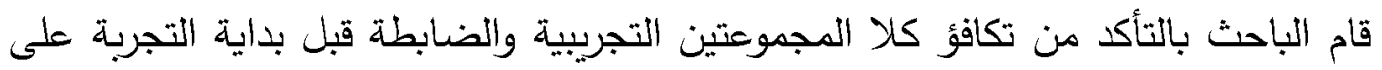
النحو التالي: - n

العمر:بالرجوع إلى سجلات الطلاب في المدرسة قام الباحث بتدوين أعمار طلاب المجموعتين التجريبية والضابطة - عينة الدراسة- وذلك للتأكد من عدم وجود فروق ذات دلالة إحصائية بين المجموعتين في متغير العمر وجاءت النتائج كالتالي: الجدول Vوضتح متوسط أعمار المجموعتين بالأشهر

\begin{tabular}{|c|c|c|c|c|c|c|}
\hline الدلالة & قيمة ت & الانحر اف & المتوسط & العدد & الفئة & المتغير \\
\hline \multirow[t]{2}{*}{$.0 Y T$} & \multirow[t]{2}{*}{$.7 \leq \varepsilon$} & $1 . \wedge 9 \mu$ & $190 . .$. & ro & التجريبية & \multirow[t]{2}{*}{ العمر } \\
\hline & & $r .09$ & $19 \varepsilon .7 \varepsilon$ & ro & الضابطة & \\
\hline
\end{tabular}


فاعلية توظيف الموديولات التعليمية في تدريس مادة النحو على زيادة التحصيل الدراسي واتجاه طلاب الصف الثاني أ أعبدالعزيز بن إبراهيم العمبري

الثانوي نحوها

يتضح من خلا النتائج الموضحة أعلاه عدم وجود فروق ذات دلالة إحصائية عند

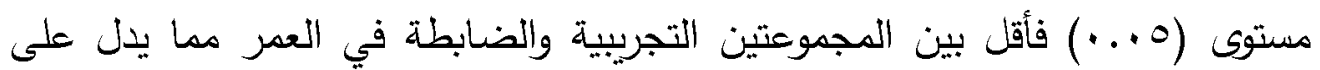
تكافؤ المجموعتين.

التحصيل الدراسي:قام الباحث بالرجوع إلى نتائج الطلاب النهائية في كلا المجموعتين

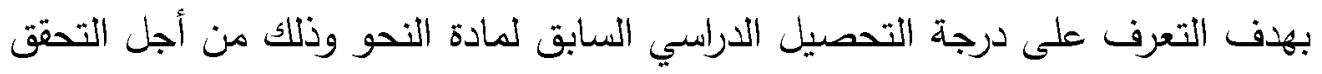
من تكافؤ المجموعتين،وجاءت النتائج كما يوضحها الجدول التالي: الجدول ^ يوضح الـ فروق بين المجموعتين التجربية والضابطة في التحصيل الدراسي

\begin{tabular}{|c|c|c|c|c|c|c|}
\hline الدلالة & قيمة ت & الانحر اف & المتوسط & العدد & الفئة & المتغير \\
\hline \multirow[t]{2}{*}{$\because V 1 \cdot$} & \multirow[t]{2}{*}{ r rVo } & $\varepsilon .9 . r$ & $V I . V Y$ & ro & التجريبية & \multirow[t]{2}{*}{ التحصيل الدر اسي } \\
\hline & & ร.91. & VY.YE & Yo & الضابطة & \\
\hline
\end{tabular}

يتضح من خلال النتائج الموضحة أعلاه عدم وجود فروق ذات دلالة إحصائية عند هستوى (0. . •) فأقل بين المجموعتين التجريبية والضابطة في التحصيل الاراسي القبلي مما يؤكد تكافؤ المجموعتين التجريبية والضابطة وصلاحيتهما لتطبيق التجربة. امتلاك جهاز الحاسب الآلي:اتضح من خلال نتائج التحليل أن المجموعتين التجربيية والضابطة متشابهتان من حيث امتلاك أفرادها لأجهزة الحاسب الآلي حيث بين اختبارمربع كايعدم وجود فروق بين المجموعتين في متغير امتلاك جهاز الحاسب الآلي. الجدول 9 يوضتح نسبة امتلاك الطلاب لجهاز الحاسب الآلي فئي

\begin{tabular}{|c|c|c|c|c|}
\hline \multirow{2}{*}{ الاحصائسة الدلالة } & \multirow{2}{*}{ قيمة مربع } & \multicolumn{2}{|c|}{ امتلاك جهاز حاسب في المنزل } & \multirow[t]{2}{*}{ المجمو عة } \\
\hline & & نسبة & تكر ار & \\
\hline \multirow[t]{2}{*}{$1 . \cdots$} & \multirow[t]{2}{*}{$\because$} & $0 / 01 \cdots$ & ro & التجريبية \\
\hline & & $\% 1+\ldots$ & ro & الضـابطة \\
\hline
\end{tabular}

التطبيق القبلي:للتعرف على ما إذا كانت هناك فروق ذات دلالة إحصائية بين التطبيق القبلي عند مستويات بلوم ككل للمجموعتين التجريبية والضابطة استخدم الباحث اختبار (ت) لعينتين مستقلتين "IndependentSample T-test " وجاءت النتائج كما يوضحها الجدول التالي: 
فاعلية توظيف الموديولات التعليمية في تدريس مادة النحو على زيادة التحصيل الدراسي واتجاه طلاب الصف الثاني أ أعبدالعزيز بن إبراهيم العمبري

الثانوي نحوها

الجدول ا يوضح الفروق بين المجموعتين التجربيية والضابطة في التطبيق القبلي

\begin{tabular}{|c|c|c|c|c|c|c|}
\hline الدلالة & قيمة ت & الانحر اف & العدد & المتوسط & المجمو عة & المتغير \\
\hline \multirow[t]{2}{*}{$\because .01$} & \multirow[t]{2}{*}{$1.9 \leq 0$} & r.07 & ro & IY.VT & الضـابطة & \multirow{2}{*}{ للمجمو عتين القبلي } \\
\hline & & T. T & ro & $1 \leqslant .7 \varepsilon$ & التجر بيبة & \\
\hline
\end{tabular}

يتضح من خلال النتائج الموضحة أعلاه عدم وجود فروق ذات دلالة إحصائية عند مستوى(0 +. .) فأقل بين متوسط درجات طلاب المجموعة التجربيية وبين متوسط درجات طلاب المجموعة الضـابطة في التطبيق القبلي، وهذا يؤكد تكافؤ المجموعتين. تنفيذ التجربة:

تطبيق الموديولات التعليمية:بدأ الباحث في الأسبوع الأول بتعريف عام بالموديولات التعليمية وطريقة السير فيها من خلال عرض تقديمي "بوربوينت، وذلك استعدادا لبذه التجربة الأسبوع التالي. • قام الباحث بإعداد نسخة من الموديولات التعليمية تسلم لكل طالب سبت كل أسبوع وذلك بعد إجراء الاختبار القبلي للموديول، ثم يقوم الطالب بدراسة الموديول لمدة يوم واحد بعدها يتم تنفيذ الاختبار البعدي للموديول يوم الاثنين من كل أسبوع ، وهكا مع بقية الموديولات، وهذه الطريقة تعطي الطالب القرصة للاستفادة من مراجع الموديول ومواده الإثرائية وتساعده على إتقان الموديولالتعليمي،كما أنها لاتحدث خلال في الجدول الاراسي. تطبيق الاختبار التحصيلي: بعد التأك من صلخحية الاختبار للتطبيق، تم تطبيقه قبليا

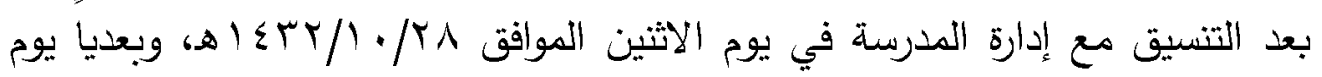

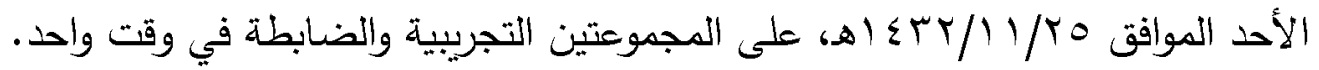
تطبيق مقياس الاتجاهات : بعد التأكد من دقة المقياس وصلاحيته للتطبيق، تم تطبيقه

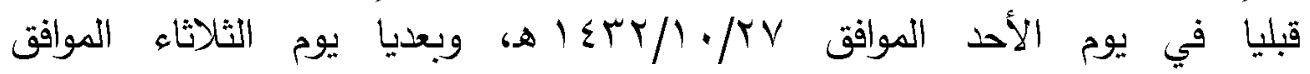

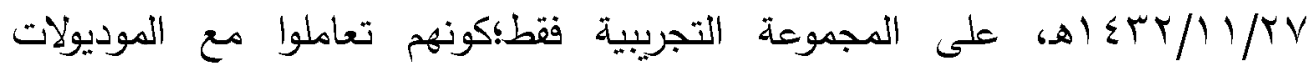
التعليمية، ويمكن في ضوه ذلك قياس اتجاهاتهم نحو تعلم مادة النحو قبل تطبيق التجربته وبعدها. 
فاعلية توظيف الموديولات التعليمية في تدريس مادة النحو على زيادة التحصيل الدراسي واتجاه طلاب الصف الثاني أ أعبدالعزيز بن إبراهيم العمبري

الثانوي نحوها

للاجابة عن السؤال الأول: ما فاعلية استخدام الموديولات التعليمية في تدريس مادة النحو على تنمية التحصيل الدراسي لاى طلاب الصف الثاني الثانوي:لإجابة على هذا السؤال قام الباحث بإجراء ثلاث مقارنات.الأولى:كانت بين الأداء القبلي والبعدي لأبي عند مستوي اتبلوم ككل، لطلاب المجموعة التجربية، وذلك بغرض التحقق من وجود أي تحسن في مستوى المجموعة يعزى إلى تدريها باستخدام الموديولات التعليمية ، الثانية: كانت بين الأداء القبلي والبعدي عند مستوي اتبلوم ككل، لطلاب المجموعة الضابطة،وذلك بغرض التحقق من وجود أي تحسن في مستوى المجموعة يعزى إلى تدريسها باستخدام الطريقة التقليدية. الثالثة: كانت بين المجموعتين التجريبية والضابطة عند مستوي اتبلوم ككل في الاختبار البعدي،وذلك حتى يستطيع الباحث الحكم على أن بأن التغيير الذي حدث لاى المجموعة التجريبية كان نتيجة لتدريها باستخدام الموديولات

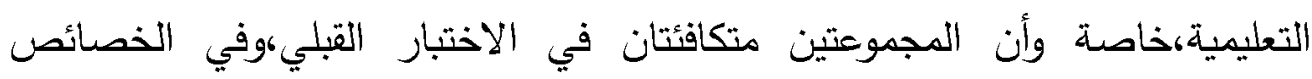
الشخصية،هما يجعل الاختلاف الوحيد بينهما في أسلوب التدريس المستخدم،وبالتالي فإن أي تغيرات تحدث في مستوى المجموعة التجريبية تعزى إلى تدربسها باستخدام الموديولات التعليمية،وهذه المقارنات تظهر نتائجها في الجداول التالية: القروق بين الاختبارين القبلي والبعدي عند مستويات بلوم ككل للمجموعة التجريبية:للتعرف على ما إذا كانت هنالك فروق ذات دلالة إحصائية بين الاختبارين القبلي والبعدي عند مستويات بلوم ككل للمجموعة التجريبية استخدم الباحث اختبار (ت) لعينتين مرتبطتين "Paired Samples T-test" وجاءت النتائج كما يوضحها

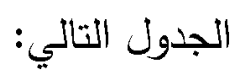

الجدول |ل يوضح الفروق بين الاختبارين القبلي والبعدي عند مستويات بلوم ككل

للمجموعة التجريبية

\begin{tabular}{|c|c|c|c|c|c|c|}
\hline الدلالة & قيمة ت & الانحر اف & العدد & المتوسط & التحصبل & \\
\hline \multirow[t]{2}{*}{$* * \ldots$} & \multirow[t]{2}{*}{$V . \Sigma \cdot Y$} & T.YTE & TO & $1 \leqslant .7 \varepsilon$ & القبلي & \multirow[t]{2}{*}{ الموديو لات التعليمية } \\
\hline & & E.TY. & ro & $r \cdot .7$. & البعدي & \\
\hline
\end{tabular}


فاعلية توظيف الموديولات التعليمية في تدريس مادة النحو على زيادة التحصيل الدراسي واتجاه طلاب الصف الثاني أ/عبدالتعزيز بن إبراهيم العمبري

الثانوي نحوها

" *روق دالة عند مستوى ا +.. فأقلى

يتضح من خلال النتائج الموضحة أعلاه وجود فروق ذات دلالة إحصائية عند مستوى(1 +. فأقل بين الاختبارين القبلي والبعدي عند مستويات بلوم ككل لصالح الاختبار البعدي؛ مما يؤكد وجود تحسن كبير وذو دلالة إحصائية في تحصيل طلاب المجموعة التجريبية لمادة النحو، ويعزو الباحث هذا التحسن إلى استخدام الموديولات التعليمية في تدريسها. الفروق بين الاختبارين القبلي والبعدي عند مستويات بلوم ككل للمجموعة الضابطة:للتعرف على ما إذا كانت هنالك فروق ذات دلالة إحصائية بين الاختبارين القبلي والبعدي عند مستويات بلوم ككل للمجموعة الضابطة استخدم الباحث اختبار (ت) لعينتين مرتبطتين Paired Samples T-test" وجاءت النتائج كما يوضحها

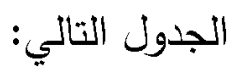

الجدول rا يوضتح الفروق بين الاختبارين القبلي والبعدي عند مستويات بلوم ككل للمجموعة الضابطة

\begin{tabular}{|c|c|c|c|c|c|c|}
\hline الدلالة & قيمة ت & الانحر اف & العدد & المتوسط & التحصيل & \\
\hline \multirow{2}{*}{$\because \leqslant 0$} & \multirow{2}{*}{$\because \vee 9 \leq$} & $r .07 r$ & ro & $1 Y . V 7$ & القبلي & \multirow{2}{*}{ طريقة التدريس } \\
\hline & & $\varepsilon .1$. & ro & M. $\varepsilon$. & البعدي & \\
\hline
\end{tabular}

يتضح من خلال النتائج الموضحة أعلاه عدم وجود فروق ذات دلالة إحصائية عند مستوى (0. . ) فأقل بين الاختبارين القبلي والبعدي عند مستويات بلوم ككل، مما يؤكد عدم وجود تحسن ذو دلالة إحصائية في تحصيل طلاب المجموعة الضابطة لمادة النحو، ويعزو الباحث هذه النتيجة إلى طريقة التدريس المستخدمة التي تعتمد دهد دله على التلقين وتقلل من إيجابية الطالب. الفروق بين المجموعتين التجريبية والضابطة في الاختبار البعدي عند مستويات بلوم ككل:لاختبار صحة الفرض الأول هن فروض الدراسة والذي ينصُّ على أنه" لا توجد فروق ذات دلالة إحصائية عند مستوى (0 ...) بين متوسط درجات طلاب المجموعة التجريبية، ومتوسط درجات طلاب المجموعة الضدبطة في التحصيل البعدي بعد 
فاعلية توظيف الموديولات التعليمية في تدريس مادة النحو على زيادة التحصيل الدراسي واتجاه طلاب الصف الثاني

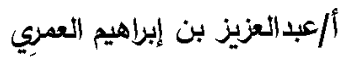

الثانوي نحوها

Independent الضبط القبلي" استخدم الباحث اختبار (ت) لعينتين مستقلتين " Sample T- test" الجدول rا يوضح الفروق بين المجموعتين التجريبية والضابطة في الاختبار البعدي

\begin{tabular}{|c|c|c|c|c|c|c|}
\hline \multicolumn{7}{|c|}{ عند مستويات بلوم } \\
\hline الدلالة & قيمة ت & الانحر اف & المتوسط & العدد & المجمو عة & \\
\hline \multirow[b]{2}{*}{$\begin{array}{r}\cdot \cdots \\
\\
* * *\end{array}$} & \multirow[b]{2}{*}{$7.1 \cdot V$} & $\varepsilon_{6} \cdot 1$ & Ir. & ro & الضـابطة & فاعلية استخدام \\
\hline & & E, $\varepsilon_{T}$. & Y. . T. & ro & التجرييية & التعوديوية لات \\
\hline
\end{tabular}

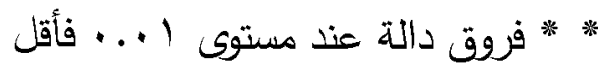

يتضح من خلال النتائج الموضحة أعلاه وجود فروق ذات دلالة إحصائية عند مستوى (1 (.) فأقل بين متوسط درجات طلاب المجموعة التجريبية، ومتوسط درجات طلاب المجموعة الضابطة في التحصيل البعدي لصالح المجموعة التجربية؛؛ وهذا يقود إلى رفض الفرض الصفري الذي ينص على أنه" لا توجد فروق ذات دلالة إحصائية عند مستوى (0...) بين متوسط درجات طلاب المجموعة التجريبية، ومتوسط درجات طلاب المجموعة الضابطة في التحصيل البعدي بعد الضبط القبلي".ويعزو الباحث هذه

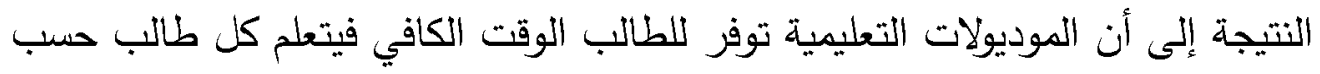
ق دراته واستعداداته، إضافة إلى التفاعل الإيجابي أثثاء عملية التعلم، وتراعي الثروق الفردية بين الطلاب، كما أنها تراعي الحرية في اختيار وقت التعلم ومكانه، ولتميزها

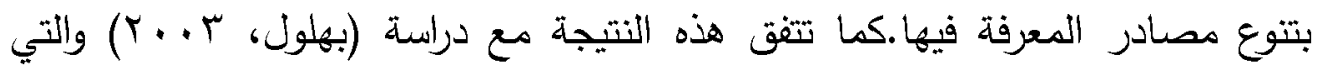
بينت وجود فروق دالة إحصائيا عند مستوى (1 (..) بين درجات طلاب المجموعة التجريبية والضابطة في التحصيل الدراسي لصالح المجموعة التجريبية ، ولم تختلف عنها دراسة(الجرواني، r + . F ) والتي بينت وجود فروق دالة إحصائياً في الاختبار التحصيلي البعدي لصالح المجموعة التجريبية في مستوى التحصيل المعرفي مما يدل على فاعلية الموديولات التعليمية، وهي ذات التتيجة التي أكدتها دراسة ( المهاي، ع . . ) والتي بينت وجود فروق ذات دلالة إحصائية عند مستوى (0...) بين 
فاعلية توظيف الموديولات التعليمية في تدريس مادة النحو على زيادة التحصيل الدراسي واتجاه طلاب الصف الثاني أ أعبدالعزيز بن إبراهيم العمبري

الثانوي نحوها

متوسطي درجات طلاب المجموعة التجريبية التي تدرس باستخدام الموديولات الكمبيوترية متعددة الوسائط والمجموعة الضابطة في الاختبار التحصيلي المعرفي المرتبط بمقرر صيانة الحاسب الآلي لصالح المجموعة التجريبية ترجع إلى الأثر

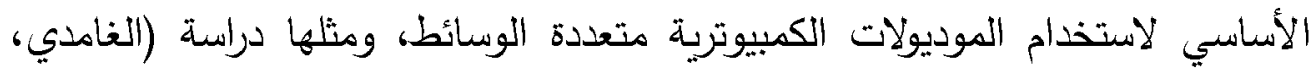
A . . r) والتي أوضحت أن الوحدات التعليمية الصغيرة(الموديولات) ذات فاعلية عالية على رفع التحصيل العمي لمقرر أسس وبرامج التربية البدنية مما أدى إلى تقارب النسبةالمئوية في مستوى التحصيل لطلاب عينة الدراسة، كما تتقق مع دراسة

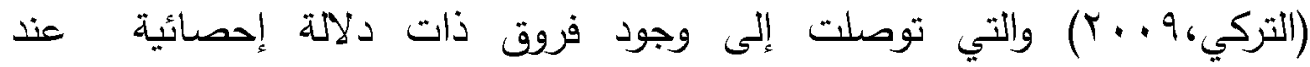
مستوى( •، ( •) بين المجموعتين التجريبية و الضابطة في الاختبار البعدي لمستويات (التذكر والفهم والتطبيق)لكل مستوى على حدة،وللمستويات الثلاثة مجتمعةبوذلك لصالح طلاب المجموعة التجريبية التي تم تدريسها باستخدام الموديولات التعليمية، ولم تختلف عنها دراسة (ثناء ياسين، • ( + إ) والتي بينت وجود فروق ذات دلالة إحصائية بين متوسط درجات المجموعة التجريبية ومتوسط درجات المجموعة الضابطة في التحصيل الدراسي لصالح المجموعة التجريبة، وتتقق دراسة (مها الصبحي، r +. r) مع ماسبق والتي أكدت وجود فروق ذات دلالة إحصائية بين متوسط درجات طالبات المجموعة التجريبية ومتوسط درجات طالبات المجموعة الضابطة في الاختبار

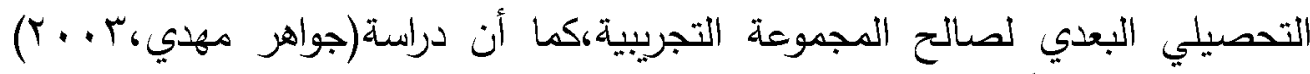
اتفقت معها أيضا على فعالية المجمعات التعليمية في علاج الأخطاء الإملائية الثائعة عند الطالبات المعلمات، لوجود فروق ذات دلالة إحصائية بين متوسطي درجات الاختبار القبلي والبعدي لصالح الاختبار البعدي، كما أن دراسة (الزهراني،ج + . ..)، بينت وجود فروق ذات دلالة إحصائية عند مستوى( (+..) في التحصيل البعدي في المهارات اللغوية مجتمعة لصالح المجموعة التجريبية. السؤال الثاني: ما فاعلية استخدام الموديولات التعليمية في تدريس مادة النحو على تنمية الاتجاه نحو المادة لدى طلاب الصف الثاني الثانوي؟ 
فاعلية توظيف الموديولات التعليمية في تدريس مادة النحو على زيادة التحصيل الدراسي واتجاه طلاب الصف الثاني أ أعبدالعزيز بن إبراهيم العمبري

الثانوي نحوها

للتعرف على فاعلية استخدام الموديولات التعليمية في تدريس مادة النحو على تنمية الاتجاه نحو المادة لاى طلاب الصف الثاني الثانوي، قام الباحث بإجراء مقارنة بين التطبيق القبلي والبعدي لمقياس الاتجاه لطلاب المجموعة التجرببية، وذلاك بغرض التحقق من وجود أي تحسن في اتجاهات الطلاب نحو مادة النحو يعزى إلى تدرسها باستخدام الموديولات التعليمية. لاختبار صحة الغرض الثاني من فروض الاراسة والذي ينصُّ على أنه " لا توجد فروق ذات دلالة إحصائية عند مستوى (0. (.) بين متوسط درجات طلاب المجموعة التجريبية في التطبيق القبلي والبعدي لمقياس الاتجاه نحو المادة".ستخدم الباحث اختبار (ت) لعينتين مرتبطتين "Paired يوضحها الجذول التالي: الجدول \& ا يوضح الفروق بين التطبيق القبلي والبعدي لمقياس الاتجاه نحو المادة

\begin{tabular}{|c|c|c|c|c|c|c|}
\hline الدلالة & قيمة ت & الانحر اف & المتوسط & العدد & المقباس & \\
\hline \multirow{2}{*}{$\begin{array}{r}.6 .11 \\
*\end{array}$} & \multirow[t]{2}{*}{$r_{6} 0 \leqslant r_{-}$} & $.649 V$ & $r_{6} 9$. & ro & القبلى & \multirow{2}{*}{ نحق المادة الاتجاه } \\
\hline & & . & $\left.\Gamma_{6}\right) \varepsilon$ & ro & البعدي & \\
\hline
\end{tabular}
* فروق دالة عند مستوى ه . . . فأقل يتضح من خلا النتائج الموضحة أعلاه وجود فروق ذات دلالة إحصائية عند مستوى (0 . . فأقل بين التطبيقين القبلي والبعدي لمقياس الاتجاه نحو المادة لصالح التطبيق البعدي مما يدل على فاعلية استخدام الموديولات التعليمية في تتمية الاتجاه نحو مادة النحو لاى طلاب الصف ا لثاني الثانوي ؛ وهذا يقود إلى رفض الفرض الصفري الذي ينص على أنه " لا توجد فروق ذات دلالة إحصائية عند مستوى (ه... ) بين متوسط درجات طلاب المجموعة التجريبية في التطبيق القبلي والبعدي لمقياس الاتجاه نحو المادة" • وتدل هذه التتيجة على أن هناك اتجاها إيجابيا نحو تعلم مادة النحو لاى طلاب المجموعة التجريبية يعزى إلى استخدام الموديولات التعليمية في تدربهح ، مما أسهم في زيادة اتجاهاتهم الايجابية نحو هذه المادة.كما تتفق هذه النتيجة مع دراسة 
فاعلية توظيف الموديولات التعليمية في تدريس مادة النحو على زيادة التحصيل الدراسي واتجاه طلاب الصف الثاني أ أعبدالعزيز بن إبراهيم العمبري

الثانوي نحوها

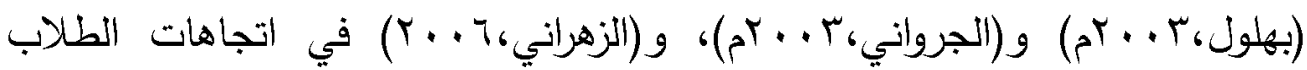

الإي جابية عقب دراستهم المحتوى التعليمي باستخدام الموديولات التعليمية .

توصيات الدراسة:

في ضوء ماأسغرت عنه الدراسة الحالية من نتائج،فإنه يمكن تقديم التوصيات التالية: ( ) تضمين مهارات استخدام الموديولات التعليمية في التدريس ضمن مقررات

ومناهج تأهيل المعلمين.

r) إقامة ورش العمل والندوات حول تعليم اللغة العربية في مراحل التعليم العام (الواقع والتصورات المستقبلية يعنى بالتركيز على واقع تعليم اللغة العربية، وسبل تطويره في ضوه المستجدات، والاتجاهات الحديثة.

r) إجراء تقويم دوري لواقع استخدام معلمي اللغة العربية لأساليب التعلم الذاتي الحديثة وذلك لمواجهة تحديات العصر .

ع) الدعوة إلى تأسيس بنك للموديو لات التعليمية يمكن الحصول منه على موديولات تعليمية جاهزة للاستخدام في جميع المجالات الاراسية للمراحل التعليمية المختلفة وذلك لمواكبة الاتجاهات العالمية الحديثة في التعليم. الاراسات المقترحة . المات ا. . بناء على النتائج السابقة التي توصلت إليها هذه الدراسة فإن الباحث يقترح

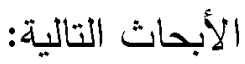

r. دراسة فاعلية الموديولات التعليمية في تنمية مهارات التذوق الأدبي، وتحليل النصوص الأدبية لاى طلاب المرحلة الثانوية. r. القيام بالمزيد من الدراسات المستقبلية حول واقع استخدام الموديولات التعليمية في تدريس مادة النحو لطلاب مراحل التعليم العام. 
فاعلية توظيف الموديولات التعليمية في تدريس مادة النحو على زيادة التحصيل الدراسي واتجاه طلاب الصف الثاني أ أعبدالعزيز بن إبراهيم العمبري

الثانوي نحوها

\section{مراجع الدراسة:}

- إبراهيم ، مجدي عزيز • (ع · • rم) • استراتيجيات التعليم وأساليب التعلم . القاهرة : مكتبة الأنجلو المصرية.

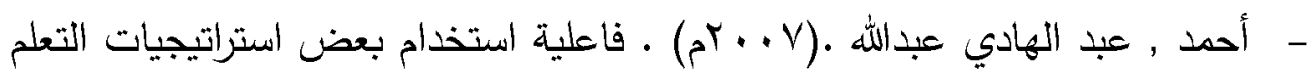
النشط في تدريس مادة الاقتصاد على التحصيل والاتجاه نحو مادة لدى طلاب المرحلة الثانوية بسلطنة عمان ـ دراسات في المناهج وطرق التدريس ـ كلية التربية

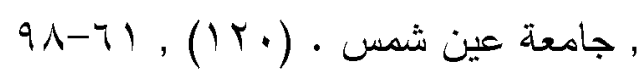

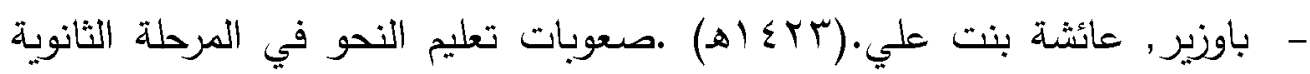
من وجهة نظر المعلمات والمشرفات التربويات • رسالة ماجستير غير منشورة كلية التربية , جامعة الملك سعود , الرياض. نطر.

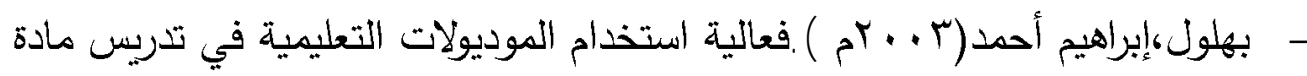
المناهج في كل من التحصيل الاراسي والاتجاه نحو التعلم الذاتي وتحقيق الذات لاى طلاب الدراسات العليا تخصص اللغة العربية ،مجلة كلية التربية ،عدد يناير

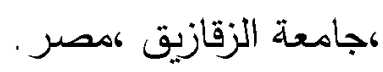

- جامل، عبدالرحمن عبدالسلام .(r ..rم).التعلم الذاتي بالموديولات التعليمية اتجاهات معاصرة. عمان : دار المناهج. - الجندي, علياء عبدالله. (0. + rم). فعالية الوحدات النسقية في تنمية كفايات توظيف تكنولوجيا المعلومات لاى معلمي ومعلمات المرحلة الثانوية بالمملكة العربية السعودية. مجلة جامعة أما لقرى للعلوم التربوية والاجتماعية والإنسانية,

$$
\text { .I I E V • • (1) }
$$

- الاعدي , سها بنت دخيل الله . (9. . r م) • فعالية استخدام خرائط المفاهيم وخرائط المفاهيم المعززة بالعروض التقديمية (الحاسب الآلي)في تحصيل قواعد اللغة العربية لاى تلميذات الصف الرابع الابتدائي • رسالة ماجستير غير منتورة . كلية التربية ، جامعة أم القرى , مكة المكرمة. 
فاعلية توظيف الموديولات التعليمية في تدريس مادة النحو على زيادة التحصيل الدراسي واتجاه طلاب الصف الثاني أ/عبدالتعزيز بن إبراهيم العمبري

الثانوي نحوها

- الاليمي ، طه وآخرون • ( r + rrم) .اللغة العربية مناهجها وطرائق تدريسها . عمان : دار الثروق للنشر والتوزيح. - - الاليمي ، طه وآخرون • ( ع · ·r ).أساليب حديثة في تدريس قواعد اللغة العربية

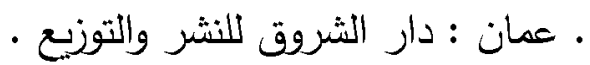

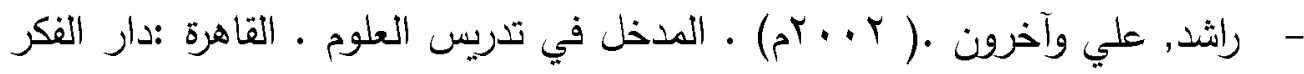
العربي. - الرافعي , محب محمود وصبري , ماهر إسماعيل · (T+..rم) • التقويم التربوي

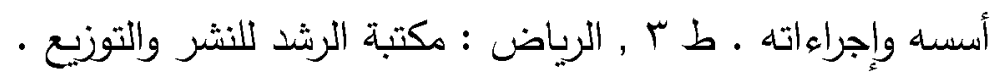
- الزغول , عماد عبد الرحيم.(r +. r م) ـ مبادئ علم النفس التربوي ـ ط r, العين • - زيتون , كمال عبدالحميد .(r+..rم) • تكنولوجيا التعليم في عصر المعلومات والاتصالات ـ القاهرة : عالم الكتب . - السليتي, فراس. (^ . . r م) .التعلم المبني على الدماغ رؤى جديدة تطورات مبكرة. إربد : عالم الكتب.

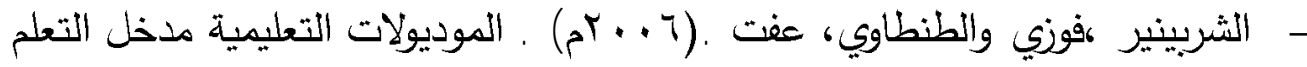
الذاتي في عصر المعلوماتية ، القاهرة : مركز الكتاب للنشر .

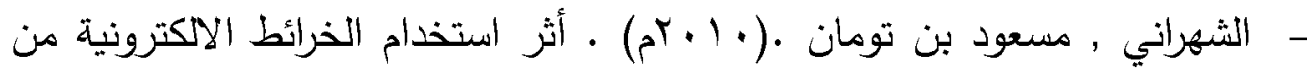

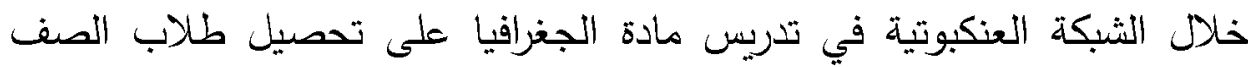
الثاني المتوسط بمحافظة بيشة واتجاهاتهم نحوها ـ رسالة دكتوراه غير منشورة. كلية التربية ،جامعة أم القرى, مكة المكرمة . - طعيمة , رشدي أحمد • ( 0. . بم) . مناهج اللغة العربية في مجتمع القراهة . المؤتمر العمي السابع عشر لمناهج التعليم والمستويات المعيارية , الجمعية المصرية للمناهج وطرق التدريس , (1) , 9-VV • (1 . 
فاعلية توظيف الموديولات التعليمية في تدريس مادة النحو على زيادة التحصيل الدراسي واتجاه طلاب الصف الثاني

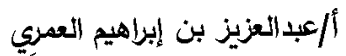

الثانوي نحوها

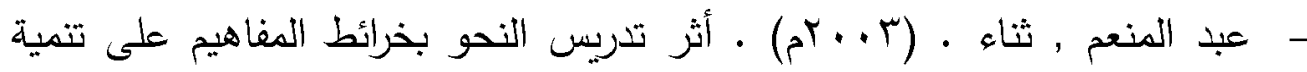
مهارات الإنتاج اللغوي والاتجاه نحو المادة لاى طلاب الصف الأول الإعدادي .

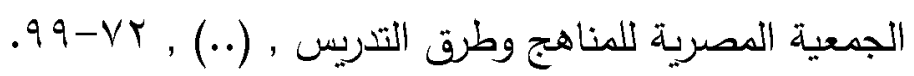

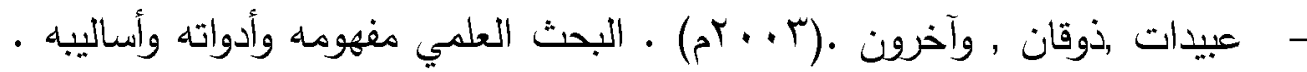
الرياض:دار أسامة.

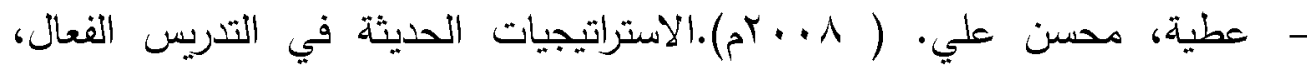
عمان: دار صفاء للنشر والتوزيع.

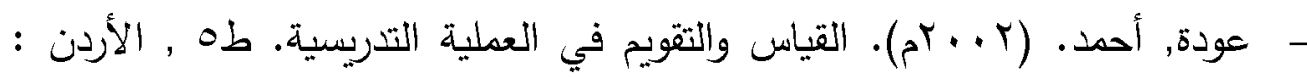

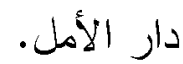

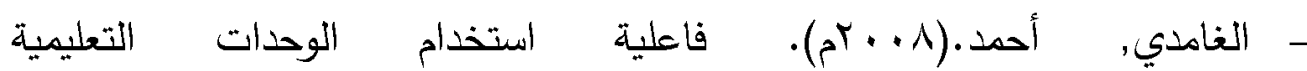
الصغيرة(الموديولات)على تحصيل طلاب كليات المعلمين في مقرر أسس وبرامج

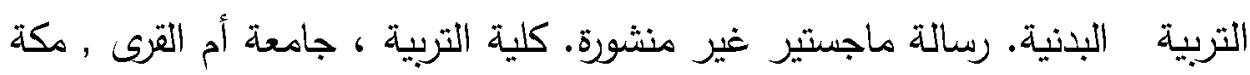
المكرمة. - القرني,مهدي بن علي • (r . .rم) • أثر تدريس وحدة مقترحة في النحو العربي قائمة على الأساليب المعرفية على التدصيل اللغوي لاى طلاب الصف الثالث

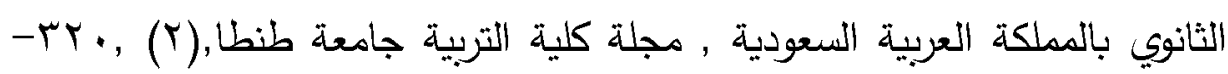

$$
. \mathrm{r} O \mathrm{~N}
$$

- كامل , عبدالرحمن • (0. ㄷم) .مهارات التفكير النازمة لتدريس النحو : مدى توافرها لاى الطالب المعلم ، وكيفية إكسابه إياها ، وأثرها على تحصيل طلابا لصف الأول الثانوي العام. رسالة ماجستير غير منشورة. جامعة القاهرة، معها وهابه الدراسات والبحوث التربوية، القاهرة.

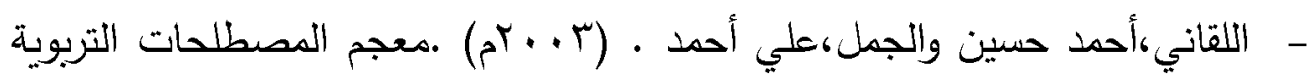
في المناهج وطرق التدري. طس، عالم الكتب: القاهر5. 
فاعلية توظيف الموديولات التعليمية في تدريس مادة النحو على زيادة التحصيل الدراسي واتجاه طلاب الصف الثاني أ أعبدالعزيز بن إبراهيم العمبري

الثانوي نحوها

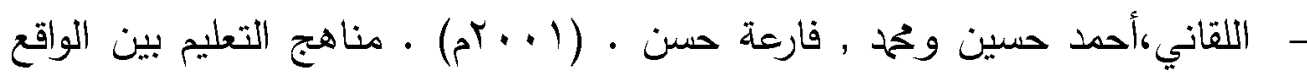
والمستقبل . القاهرة : عالم الكتب .

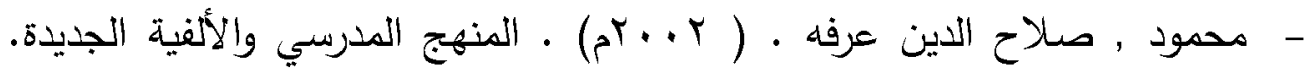
القاهرة: دار القاهرة .

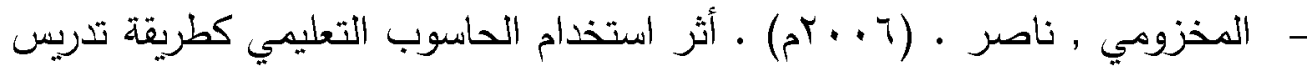
في اكتساب المفاهيم النحوية لاى طلاب الصف الأول الثانوي ( أدبي ) , دراسات

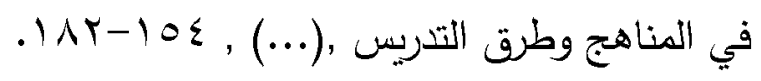

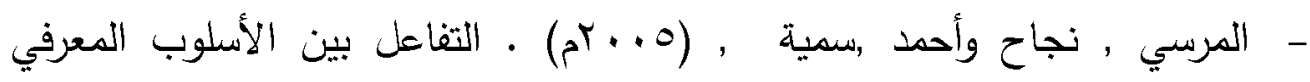
والموديولات التعليمية في العلوم وأثره على التحصيل وقلق الاختبار لاى تلاميذ

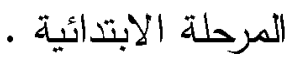
- المعايطة، خليل عبدالرحمن .V) . . (Yم).علم النفس الاجتماعي.طY،الأردن: دار الفكر - المعمري , فاطمة يوسف . ( ع . . rم) .أثز التدريس بالاكتشاف في تحصيل العلوم وتنمية عمليات العلم لدى طالبات الصف التاسع من التعليم العام •رسالة ماجستير غير منثورة .كلية التربية . جامعة السلطان قابوس , مسقط .

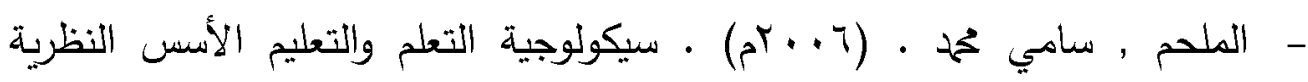

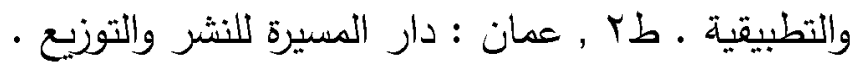

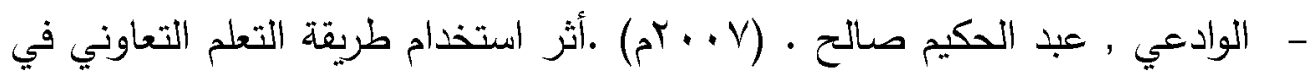
تحصيل مادة النحو لاى طلبة المرحلةالثانوية. رسالة ماجستير غير منشورة ـ كلية التربية , جامعة صنعاء , اليمن •

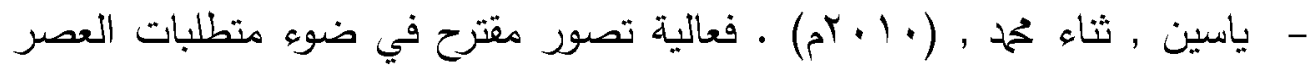
قائم على التعلم الفردي الذاتي باستخدام الموديولات التعليمية على التحصيل الدراسي وبقاه أثثره على التعلم في العلوم التجريبية لاى طالبات الصف الثالث الثردئ

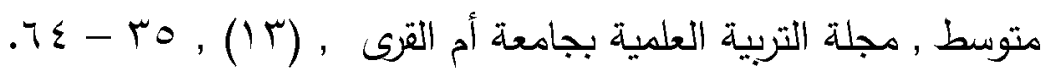


فاعلية توظيف الموديولات التعليمية في تدريس مادة النحو على زيادة التحصيل الدراسي واتجاه طلاب الصف الثاني الثانوي نحوها

- Bolka, D.(2003 ) Mathematics Manipulative in a PreVocational /Program Teacher In-service and Classroom Research. U.S.A. Indiana Dis., Abs., Int.,.

- Corn , J. (2001 ) Mathematics Applications in Technology ,Students' Achievement and Attitudes Dis., Abs. ,In,Vol,42,No,4.

- Hernandez, G ( 2008 ) Effects of teaching problem- solving thought cooperative learning methods on student mathematics achievement attitudes towards mathematics self - efficacy and meta cognition. Dis.,Abs.,Int.,. Vol ,158, No , 8 .

- Soeharto, S(2009) The Effects of constructivist learning environment on grade six student achievement and attitude toward mathematics in Indonesian Primary schools Dis., Abs., Int. 